\title{
Artículos
}

\section{Factores del deterioro de las áreas naturales protegidas periurbanas del Valle de Puebla, México}

\section{Factors of deterioration of the periurban protected natural areas of the Valley of Puebla, Mexico}

\author{
Margarita Tlapa Almonte \\ Ángel Bustamante González \\ Samuel Vargas López ${ }^{\mathrm{c}}$ \\ Benito Ramírez Valverded \\ Virginia Cervantes Gutiérrez \\ Gustavo Cruz Bello ${ }^{\mathrm{f}}$
}

\section{Resumen}

En la interfase ciudad-comunidades rurales del área metropolitana del Valle de Puebla se tienen establecidas siete áreas naturales protegidas periurbanas. El objetivo de esta investigación fue tener un diagnóstico exploratorio de su condi-

a REZAC, Reserva Ecológica Zapotecas, A.C. Dirección: Municipio San Pedro Cholula, Puebla. Correo: mtlapa@gmail.com ORCID: https://orcid.org/0000-0001-5517-3927

b Colegio de Postgraduados, campus Puebla. Dirección: Boulevard Forjadores de Puebla, 205, Santiago Momoxpam, San Pedro Cholula, 72760, Puebla, México. Correo: angelb@colpos. mx ORCID: http://orcid.org/0000-0002-0727-9505

${ }^{\mathrm{c}}$ Colegio de Postgraduados, campus Puebla. México. Correo: svargas@colpos.mx ORCID: http://orcid.org/0000-0002-8303-3128

d Colegio de Postgraduados, campus Puebla. México. Correo: bramirez@colpos.mx ORCID: http://orcid.org/0000-0003-2482-5667

e Universidad Autónoma Metropolitana, unidad Xochimilco. Dirección: Calzada del Hueso 1100, Villa Quietud, Coyoacán, 04960, Ciudad de México, México. Correo: cervirginia@, gmail.com ORCID: https://orcid.org/0000-0002-1472-8858

${ }^{f}$ Universidad Autónoma Metropolitana, unidad Cuajimalpa. Dirección: Av. Vasco de Quiroga 4871, Santa Fe, Cuajimalpa, 05349, Ciudad de México, México. Correo: gcruz@correo. cua.uam ORCID: http://orcid.org/0000-0001-9118-6565

Nota de los autores: Agradecemos a los gobiernos municipales de Puebla, San Martín Texmelucan y San Pedro Cholula, su apoyo para la realización de esta investigación; a la Secretaría de Medio Ambiente y Recursos Naturales del Estado de Puebla por la información y cartografía digital de la región Centro-Poniente del estado; al departamento de Educación Ambiental de la Secretaría de Medio Ambiente y Recursos Naturales, delegación Puebla; a las ONG ProCholula y Reserva Ecológica Zapotecas por su disposición para proporcionar información. 
ción actual y de los factores que inciden en su pérdida territorial y deterioro ecológico. Estas áreas no están funcionando como estrategias de conservación debido a que carecen de una delimitación espacial precisa y de un plan de manejo, son desconocidas por la mayoría de los habitantes del área, carecen de un presupuesto para su gestión, hay venta de tierras y persisten las actividades productivas y extractivas.

Palabras clave: áreas naturales protegidas; áreas periurbanas; deterioro ambiental; amenazas ambientales.

\begin{abstract}
In the city-rural communities interface of the Puebla Valley seven periurban protected natural areas have been established. The objective of this investigation was to have an exploratory diagnosis of their current status and of the factors that affect their territorial loss and its ecological deterioration. These areas are not functioning as conservation strategies, because they lack a precise spatial delimitation and a management plan, they are unknown to most of the inhabitants of the area, they lack a budget for their management, the sale of lands and the productive and extractive activities.
\end{abstract}

Keywords: protected natural areas; periurban areas; environmental deterioration; environmental threats.

\title{
Introducción
}

En México, las áreas naturales protegidas (ANP) son espacios territoriales en donde se tiene como objetivo la preservación de la biodiversidad y de otros servicios ambientales. Estos espacios pretenden conservar la biodiversidad, mantener los procesos ecológicos y preservar los ecosistemas y sus recursos naturales y culturales asociados para el bienestar social (Palomo et al., 2014, p. 181; Phillips, 2003, p. 8). El decreto de las ANP es la estrategia de conservación y preservación preferida de los conservacionistas y, por lo menos en el discurso, es importante para el gobierno federal y parcialmente para los gobiernos estatales, con menor relevancia para los gobiernos municipales. Esto último ha llevado a que sea común que se utilice el concepto y la figura jurídica de las ANP con fines de promocionar una imagen gubernamental interesada por la conservación, más que por un objetivo genuino de conservación de los ecosistemas y de sus servicios ambientales y recursos naturales. Esta situación se acentúa en la interfase ciudad-comunidades rurales, en donde, como se aborda en el presente estudio, se establecen áreas protegidas a imagen y semejanza de las ANP convencionales, dando lugar a lo que nosotros llamamos áreas naturales protegidas periurbanas. Un ANP 
convencional corresponde a la definición establecida en la Ley General del Equilibrio Ecológico y la Protección al Ambiente (Diario Oficial de la Federación, 2012), que textualmente dice que son:

Las zonas del territorio nacional y aquellas sobre las que la nación ejerce su soberanía y jurisdicción, en donde los ambientes originales no han sido significativamente alterados por la actividad del ser humano, o que requieren ser preservadas y restauradas y están sujetas al régimen previsto en la presente ley.

De acuerdo con la normatividad de México, se tienen áreas naturales protegidas convencionales, que pueden ser federales, estatales o municipales, o bien áreas destinadas voluntariamente para la conservación. Se han decretado 182 ANP federales, con una superficie de 90839521.55 hectáreas, que representan el $12.1 \%$ del total del territorio nacional (Conanp, 2017). En 2009 se tenían registradas 296 ANP estatales y 98 municipales, que ocupaban una superficie aproximada de 3.3 y 0.17 millones de hectáreas, respectivamente (Bezaury-Creel y Gutiérrez, 2009, p. 417). Sin embargo, en 2015 la Comisión Nacional para el Conocimiento y Uso de la Biodiversidad reportó 421 ANP estatales y solamente 44 municipales (Conabio, 2015).

Muchas veces, los parques y reservas estatales, así como las zonas de preservación ecológica, constituyen ecosistemas urbanos y periurbanos donde es frecuente la pérdida de componentes y del funcionamiento ecológico característico de los ecosistemas naturales. Son ecosistemas parcialmente naturales y aunque aún conservan componentes originales de biodiversidad, o desempeñan un importante papel en la conservación de especies raras, tienen elementos parcialmente artificiales manejados por los seres humanos. A diferencia de las áreas naturales protegidas establecidas en espacios poco intervenidos por el hombre, cuya función se relaciona principalmente con la conservación de la biodiversidad y los servicios ambientales -como recarga hídrica y captura de carbono-, las áreas naturales protegidas establecidas en áreas periurbanas son espacios vitales con funciones sociales, económicas y emocionales; específicamente suministran servicios ambientales para mejorar la calidad de vida de la población urbana (Manolaki y Vogiatzakis, 2017, p. 129).

Las áreas naturales protegidas periurbanas nacionales no han sido reconocidas plenamente por las contribuciones que aportan a las ciudades. Mientras que para el sistema de ANP federales se tiene una estructura administrativa consolidada mediante la Comisión Nacional de Áreas Naturales Protegidas (Conanp), la administración de las ANP estales y municipales 
depende de las políticas de cada estado o municipio. De manera general, se sabe que la administración de dichas áreas, estatales y municipales, tiene limitaciones de recursos financieros y humanos, que no es prioritaria dentro de las políticas de los gobiernos locales, y que la información sobre su funcionamiento es escasa (Bezaury-Creel y Gutiérrez, 2009, p. 393). Esto se asocia a la falta de valoración, conocimiento y percepción institucional de la contribución de estos espacios para mejorar la calidad de vida de la población urbana, así como a la poca participación social y escasa concientización sobre la importancia de las ANP periurbanas. Estos factores limitan su manejo como estrategia de conservación.

Un ANP periurbana es una conceptualización más de análisis territorial que legal. En México, como en la mayor parte del mundo, no existe una definición del término periurbano en la legislación (Knuth, 2005). En este estudio se considera que un área natural protegida periurbana es una zona de transición -con un decreto gubernamental para su protección-donde interaccionan actividades rurales y urbanas, los "rasgos del paisaje están sujetos a una rápida modificación, inducida por las actividades del hombre" (Douglas, 2006, p. 18), y es parte de "la simbiosis entre el espacio natural y el espacio artificial, propio de la ciudad" (Amaya, 2005, p. 14). En estas áreas se presenta la pérdida o alteración del hábitat (degradación, fragmentación o pérdida completa) por factores biofísicos, sociales y económicos, tales como la expansión urbana y las actividades recreativas (Güneralp y Seto, 2013, pp. 6-7). Ellos disminuyen tanto la capacidad del ecosistema para mantener la biodiversidad y los procesos ecológicos, como su utilidad para el ser humano. La degradación resultante tiene efectos negativos irreversibles por la pérdida de la biodiversidad (McDonal, Marcotullio y Güneralp, 2013, pp. 36-38).

Las investigaciones sobre los factores que afectan a las ANP se han orientado tradicionalmente a los ecosistemas naturales, hábitats alejados de los centros urbanos. El término área protegida urbana no es común para la mayoría de la población y es abordado principalmente en el medio académico (Manea et al., 2016, p. 81). Los procesos de deterioro de los ecosistemas periurbanos protegidos son escasos o están poco documentados. El principal factor de deterioro documentado es la urbanización de las áreas rurales adyacentes a las ciudades, la cual introduce cambios en la función ecológica de las áreas protegidas, pérdida de su biodiversidad, cambio de uso de suelo, conflictos con la vida silvestre, introducción de especies invasivas, vandalismo y ruido, entre otros (Pauchard, Aguayo, Peña y Urrutia, 2006, pp. 273 y 277; Trzyna, 2007, pp. 9-11). Sin embargo, hay pocos estudios sobre la eficacia y el funcionamiento de las ANP periurbanas, lo que impide compa- 
rar el cambio en su condición ecológica antes y después de su establecimiento (Liu et al., 2001, pp. 100-101).

En México, los principales estudios sobre las ANP urbanas y periurbanas se concentran en la Ciudad de México. Acerca del Parque Nacional Desierto de los Leones se tienen estudios de vegetación, fauna, declinación forestal, acciones de restauración, conservación y manejo (Vargas, 1997). Sobre el ANP Cañada de los Dínamos se tiene una evaluación (Fernández, Uribe, Ramírez del Razo, Apolinar y Vázquez, 2002) y un estudio sobre ecoturismo y desarrollo sustentable (Fernández et al., 2004). Para el área protegida Sierra de Guadalupe (Cedillo, Rivas y Rodríguez, 2007, p. 2) se tienen investigaciones sobre las causas de su deterioro, así como propuestas de conservación para el aprovechamiento de los servicios ambientales generados para los habitantes de la Ciudad de México. En Xalapa, Veracruz, se han estudiado diversas y posibles fuentes de servicios ambientales en áreas verdes (www.paginasverdesxalapa.com).

El estado de Puebla actualmente tiene un total de 22 ANP ubicadas en la región Centro-Poniente del estado. Quince son de competencia federal y siete del gobierno del estado: Cerro Zapotecas, Parque Ecológico Flor del Bosque "General Lázaro Cárdenas" (664 ha), Cerro Comalo, Cerro Amalucan, Cerro Mendocina, Cerro Tepeyac y Cerro Totolqueme, todas decretadas en abril de 1994 (Periódico Oficial del Estado de Puebla, 1994).

La información que se tiene sobre las ANP periurbanas del estado de Puebla es muy limitada, a pesar de su importancia para el área metropolitana de esa entidad. En esta investigación se tuvo como objetivo principal identificar y analizar los factores que inciden en el deterioro de las siete áreas protegidas periurbanas del estado de Puebla.

\section{Materiales y métodos}

\section{Localización y características generales del área de estudio}

El área de estudio se ubica en la región Centro-Poniente del estado de Puebla, entre los paralelos $18^{\circ} 49^{\prime}$ y $19^{\circ} 24^{\prime}$ de latitud norte y los meridianos $98^{\circ} 39^{\prime}$ y 9753' de longitud oeste del meridiano de Greenwich. Está integrada por siete ANP periurbanas del Valle de Puebla (Mapa 1), decretadas como reservas ecológicas: Cerro Amalucan, localizado en el municipio de Puebla; Cerro Comalo, en el municipio de San Jerónimo Tecuanipan; los cerros Mendocinas, Tepeyac y Totolqueme, en el municipio de San Martín Texmelucan; Cerro Zapotecas, en el municipio de San Pedro Cholula, y Flor del Bosque en el 


\section{Mapa 1}

Localización de las ANP periurbanas del estado de Puebla

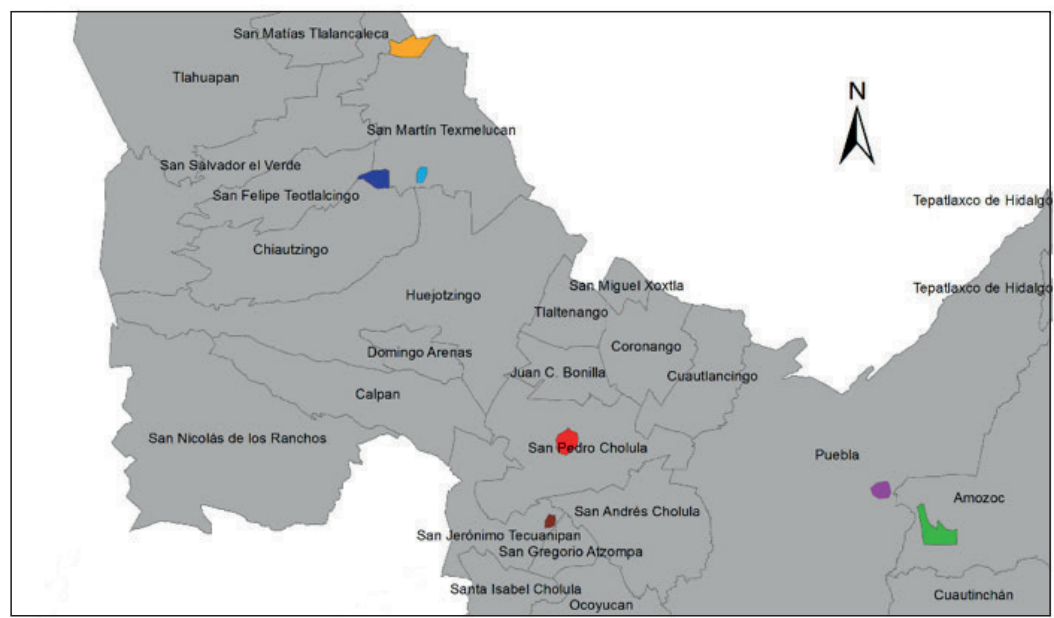

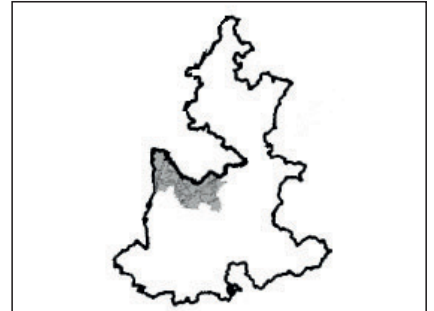

Estado de Puebla

Zona Centro-Poniente del estado de Puebla

\section{Simbología}

Cerro Amalucan

Cerro Comalo

Cerro Mendocinas

Cerro Tepeyac

Cerro Totelqueme

Cerro Zapotecas

Flor del Bosque

Fuente: Elaboración propia con datos de Sedurbecop, 2001.

municipio de Amozoc de Mota. Se caracterizan por ser en su mayoría lomas y presentan altitudes que van de los 2150 a los 2580 m (Sedurbecop, 2001; Periódico Oficial del Estado de Puebla, 1985, 1994). El tipo de clima es C( $\left(\mathrm{w}_{1}\right)$ (w) templado subhúmedo con lluvias en verano; la temperatura media anual varía entre $11^{\circ} \mathrm{C} \mathrm{y} 17^{\circ} \mathrm{C}$, con un porcentaje de precipitación invernal con respecto a la anual menor de 5\% (García, 1973, pp. 20-21). 


\section{Metodología}

El trabajo de investigación consistió en un estudio exploratorio realizado en dos etapas. En la primera se examinaron la cartografía digital y las ortofotos escala 1:75 000 (INEGI, 2001) de las siete ANP periurbanas, proporcionadas por la Secretaría del Medio Ambiente y Recursos Naturales (SMRN) del estado de Puebla. Se hizo un análisis espacial de la localización y delimitación de las ANP, verificando directamente en campo las coordenadas establecidas en las declaratorias (Periódico Oficial del Estado de Puebla, 1985, 1994 y 2008; Gobierno del Estado de Puebla, 2001). Se realizó una investigación documental para examinar las declaratorias oficiales de las ANP y los programas y proyectos relacionados con las ANP periurbanas del estado. Asimismo, se realizaron recorridos y observaciones de campo para obtener información sobre el estado actual de las ANP, la presencia de límites visibles y la pérdida territorial.

En la segunda etapa se realizó un diagnóstico exploratorio mediante la aplicación de entrevistas dirigidas e intencionales a 51 informantes clave: 20 de los entrevistados fueron actores institucionales representantes de dependencias gubernamentales ( 9 del gobierno estatal, particularmente de la Secretaría de Medio Ambiente y Recursos Naturales -SMRN- y 11 de gobiernos municipales, entre presidentes, regidores y directores de Ecología). Otros 5 entrevistados fueron autoridades locales (presidentes auxiliares); 3 representantes de organizaciones no gubernamentales (ONG); además de 15 propietarios y 8 usuarios de las ANP. En las entrevistas se obtuvo información sobre la evolución histórica y el desempeño de la declaratoria, los aspectos legales y las amenazas (factores económicos, sociales, ecológicos y políticoinstitucionales) que potencialmente pueden impedir que las ANP periurbanas cumplan con el objetivo para el cual se decretaron. Las variables económicas fueron: comercialización de tierras, extracción de recursos naturales y actividades agropecuarias. Las variables sociales: crecimiento urbano, conflictos sociales y tenencia de la tierra. Las variables ecológicas: percepción sobre la erosión, deforestación, incendios forestales y contaminación. Y las variables político-institucionales: financiamiento, recursos humanos, programas y proyectos e información documental. Se analizaron las variables a través de estadística descriptiva, mediante frecuencias de las respuestas abiertas, con la finalidad de identificar qué factores inciden en el deterioro de las áreas naturales protegidas periurbanas de la ciudad de Puebla. 


\section{Resultados}

\section{Características de los informantes clave}

Del total de entrevistados, el $82.5 \%$ fueron hombres y el $7 \%$ mujeres. La edad promedio de los informantes fue de 47.7 años. El 39.2\% de los entrevistados tiene nivel escolar de primaria y un porcentaje similar licenciatura, el $13.7 \%$ secundaria y el $5.8 \%$ preparatoria, lo que indica que la mayoría tiene un nivel educativo alto.

\section{Delimitación, ubicación y superficie de las áreas naturales protegidas}

Las ANP de competencia del gobierno del estado son: el Cerro Zapotecas, con una extensión de 536 ha, y el Parque Ecológico Flor del Bosque "General Lázaro Cárdenas", con una superficie de 664 ha. Las ANP reservas ecológicas municipales son: el Cerro Comalo (131 ha), el Cerro Amalucan (227 ha), el Cerro Mendocinas (635 ha), el Cerro Tepeyac (170 ha) y el Cerro Totolqueme (297 ha), todas declaradas en abril de 1994 (Periódico Oficial del Estado de Puebla, 1994). La delimitación de las ANP perirubanas de la entidad es confusa. Por ejemplo, las ANP de competencia municipal se registran en el Sistema Estatal de Áreas Naturales Protegidas de Puebla como áreas protegidas de jurisdicción estatal.

Otro problema encontrado fue la conceptualización y categorización de las ANP. El parque estatal es definido por la Ley para la Protección del Ambiente Natural y el Desarrollo Sustentable del Estado de Puebla, en su artículo 63, como un área

dedicada a proteger el ambiente para la recreación y protección de valor histórico, belleza escénica, científica, educativa, turismo o por razones de interés social.

La misma ley no define el término reserva ecológica señalado en la declaratoria, pero sí el de zonas de preservación ecológica de los centros de población, que son:

[...] áreas que fijan normas básicas para planear y regular la fundación, conservación y crecimiento de los centros de población, establecer provisiones, reservas, destinos y usos de predios para regular el beneficio social, el aprovechamiento de los elementos susceptibles a apropiación, para procurar la preservación y conservación del equilibrio ecológico de los centros de población [Periódico Oficial del Estado de Puebla, 1985, 1994]. 
El análisis del material cartográfico digital y las ortofotos (INEGI, 2001) mostró la incongruencia entre los datos obtenidos en campo, las declaratorias y la información documental generados por la Dirección de Planeación Ecológica de la Secretaría de Desarrollo Urbano y Obras Públicas del Estado de Puebla (Sedurbecop, 2001), proporcionados por la Secretaría del Medio Ambiente y Recursos Naturales (SMRN). Se tiene imprecisión en la localización de las ANP, existe desconocimiento de los límites precisos del área y de la superficie efectiva a ser protegida y falta un polígono definido. Esto impidió hacer una evaluación precisa de la dinámica territorial, observándose gran variación entre la superficie decretada y la estimada, además de que para todas las ANP no se especifica a qué ecosistema representan.

La declaratoria sólo menciona los nombres de las reservas ecológicas y señala la altitud, la latitud y la longitud (coordenadas) de dos puntos de referencia. No tiene información adicional relacionada con su delimitación. El Parque Ecológico Flor del Bosque cuenta con un polígono y límites definidos debido a que es administrado directamente por el gobierno del estado, y registra una superficie inicial de $614.3 \mathrm{ha}$. En el año 2000 el gobierno estatal adquirió 50 ha adicionales, lo que incrementó la superficie total del parque a 664.3 ha (Sedurbecop, 2001).

Los esfuerzos gubernamentales para precisar la delimitación de las ANP periurbanas son muy limitados. De acuerdo con la información proporcionada por representantes de los gobiernos estatal y municipal, responsables de las ANP, sólo el Cerro Zapotecas tuvo modificación en su declaratoria, a través de la coordinación de ambos. En 2006 se establecieron límites y se hizo una rezonificación de acuerdo con las necesidades actuales de conservación y protección de la biodiversidad, con el fin de detener su deterioro y hacer cumplir su objetivo. La nueva declaratoria se publicó oficialmente en noviembre de 2008 (Periódico Oficial del Estado de Puebla, 2008).

Con relación a los planes de manejo, a más de una década de haber sido declaradas ANP, no cuentan con éstos, lo que constituye una deficiencia para su funcionamiento y operatividad. Los responsables de las ANP mencionan que los planes de manejo para las reservas ecológicas no se han elaborado por falta de personal y de presupuesto. Sólo el ANP Cerro Zapotecas cuenta con plan de manejo. Para el Parque Estatal Flor del Bosque se han elaborado propuestas que no se han ejecutado, aunque la misma secretaría tiene el Programa de Manejo Integral del Parque Estatal Flor del Bosque (SMRN, 2005). La política actual del gobierno estatal es convertirlo de reserva ecológica a parque recreativo (Intolerancia, 2016). 


\section{Génesis de las AP periurbanas del estado de Puebla}

La declaratoria de las siete AP periurbanas del estado de Puebla forma parte de un proceso de planeación territorial que inició a finales de la década de los setenta como respuesta al Plan Nacional de Desarrollo (Gobierno del Estado de Puebla, 1976). La planeación tenía como propósito, de acuerdo con documentos gubernamentales en materia ambiental, el aprovechamiento, la conservación y la regeneración de los recursos naturales de la entidad; además de mejorar e incrementar los lugares de atracción recreativa con fines turísticos, las zonas boscosas y los cinturones verdes en la periferia de los centros urbanos del Valle de Puebla. En diciembre de 1985 se declaró el Parque Ecológico Recreativo "Flor del Bosque o General Lázaro Cárdenas", cuando un particular donó terrenos para el establecimiento del parque estatal (Periódico Oficial del Estado de Puebla, 1985). Posteriormente, en 1994, este parque fue declarado reserva ecológica (Periódico Oficial del Estado de Puebla, 1994).

En marzo de 1994 el gobierno estatal elaboró la declaratoria de reservas, destinos y usos de predios y áreas territoriales del Programa Regional de Ordenamiento Territorial de la Zona Centro-Poniente del Estado de Puebla, con el fin de integrar dicho territorio económica, política y ecológicamente, para beneficiar a la población rural y urbana y fortalecer la región CentroPoniente de la entidad. La declaratoria incluye las siete reservas ecológicas objeto de esta investigación. El objetivo de este decreto es servir como instrumento de planeación para ordenar y regular la fundación, la conservación y el crecimiento de dichos centros de población, así como establecer provisiones, reservas, destinos y usos de áreas de predios para regular el beneficio social. Se buscaba procurar la preservación y la conservación del equilibrio ecológico de los centros de población en el territorio del estado; es decir, fortalecer la zona conurbada de la ciudad de Puebla y los municipios de Amozoc, Coronango, Cuautlancingo, Domingo Arenas, Huejotzingo, Juan Crisóstomo Bonilla, Ocoyucan, San Martín Texmelucan, San Miguel Xoxtla, San Andrés Cholula, San Pedro Cholula y Tlaltenango (Periódico Oficial del Estado de Puebla, 1994).

Los instrumentos legales que fundamentaron y justificaron las declaratorias de las ANP periurbanas fueron la Constitución Política de los Estados Unidos Mexicanos, las leyes relacionadas con la planeación y la Ley General del Equilibrio Ecológico y la Protección al Ambiente (LGEEPA) (Sedurbecop, 2001; Gobierno del Estado de Puebla, 1999). También se justificaron las políticas, las acciones y los instrumentos operativos, y se enmarcaron en planes y programas subregionales, microrregionales, municipales y locales 
(Gobierno del Estado de Puebla, 1976, 2001; Periódico Oficial del Estado de Puebla, 1994; Sedueep, 1999).

\section{Situación actual de las ANP}

El deterioro de las ANP se ha incrementado de manera gradual en la última década. Aun cuando se reconoce su importancia por los bienes y servicios que ofrecen a la zona conurbada de la ciudad de Puebla, los recursos humanos y financieros para su administración y operación son limitados. No hay coordinación entre las instituciones gubernamentales estatales, municipales y locales para realizar programas, proyectos y actividades en las áreas protegidas. El involucramiento de la población local es casi nulo. Sin embargo, ante la presión social y las nuevas actividades socioeconómicas, dentro de las cuales se encuentra el turismo, el gobierno del estado ha retomado la administración a través de la creación de infraestructura y servicios en el Parque Ecológico Flor del Bosque. También ha fomentado actividades de reforestación y conservación del Cerro Amalucan y el Cerro Zapotecas.

\section{Amenazas a las ANP periurbanas del estado de Puebla}

Las áreas protegidas periurbanas del estado de Puebla están sujetas a presiones de índole económica, social, ecológica y político-institucional.

\section{Factores económicos}

El 58.8\% de los propietarios considera que tienen derecho al uso, manejo y aprovechamiento de los recursos naturales, como lo hacían antes del decreto. En las ANP de Mendocinas, Tepeyac, Totolqueme y Zapotecas son comunes actividades como la agricultura, el pastoreo, los incendios forestales y las prácticas extractivas. Los propietarios mencionan que, desde el pasado, la agricultura ha sido una actividad predominante en las ANP periurbanas y su entorno con fines de autoconsumo y comercial, orientada a la producción de cultivos tradicionales y de alto rendimiento (maíz, frijol, frutales, hortalizas, forrajes, plantas aromáticas y flores). Ellos reconocen que en los últimos años las áreas agrícolas de calidad han disminuido como resultado de la expansión urbana, lo que ha inducido a la ampliación de la frontera agrícola mediante la búsqueda de nuevas áreas dentro de las ANP para realizar esta actividad. 
El pastoreo, aunque actualmente ha disminuido considerablemente, se sigue practicando en Cerro Comalo -el ANP con menor superficie y con cubierta de pastizal-, Mendocinas, Tepeyac, Totolqueme y Zapotecas. Es una actividad no controlada y migrante, con un manejo inadecuado que utiliza los pastizales naturales; el tipo de ganado predominante es ovino, bovino y caprino. El $60.8 \%$ de los propietarios y responsables de las ANP entrevistados consideran que esta actividad se realiza principalmente para generar beneficios económicos adicionales mínimos, aunque reconocen que es una actividad con efectos negativos significativos sobre las ANP.

La extracción y comercialización de los recursos naturales es importante, de acuerdo con lo afirmado por el $49 \%$ de los entrevistados. Se realiza en Mendocinas, Tepeyac y Totolqueme, donde se extrae y se vende tierra y piedra, cuyo destino final es la construcción de puentes y el mantenimiento de la autopista México-Puebla. En el Cerro Zapotecas es importante la extracción de arcilla para la fabricación de ladrillo y la construcción de carreteras, como el Periférico Ecológico de la ciudad de Puebla. La extracción de flora se realiza en menor grado, con fines de autoconsumo y venta mínima. Se recolectan especies vegetales para obtener leña y madera para el autoconsumo, y se extrae fauna de forma ocasional por medio de la cacería fortuita de mamíferos. También hay captura de aves canoras en el Cerro Zapotecas para su venta. Para los pobladores locales esto representa una fuente de ingreso económico adicional e inmediato.

\section{Factores sociales}

El desarrollo urbano acelerado es la principal amenaza para las ANP periurbanas, de acuerdo con el $56.9 \%$ de los entrevistados. Se tienen asentamientos humanos irregulares en el entorno y dentro de las ANP, y es determinante la pérdida territorial. Aunque representantes de instituciones gubernamentales y ONG han censurado a los propietarios por construir o vender sus tierras, para éstos son los únicos espacios con los que cuentan para vivir y conforman su patrimonio económico, por lo que es difícil impedirles que construyan en su tierra o la vendan. El 43.1\% del total de entrevistados reconoce que la urbanización, cualquiera que sea su forma, implica la pérdida territorial del ANP, demanda mayores servicios públicos y conduce a la pérdida del territorio y de los recursos naturales útiles para el beneficio social.

El análisis demográfico muestra la importancia del desarrollo urbano como presión hacia las ANP de estudio, como lo percibió la mayoría de los entrevistados. Las ANP están situadas en áreas con una dinámica poblacional que necesariamente lleva a una mayor demanda de tierras para vivienda, 
desarrollos industriales y servicios recreativos. En la Gráfica 1 se muestra que en todos los municipios en donde se localizan las ANP se tiene un aumento poblacional sostenido, con el municipio de Puebla como el principal receptor de la creciente población. Este municipio pasó de 108765 habitantes en 1950 a 1539819 en 2010. Si bien el municipio de Puebla ha sido el de mayor población, con una tasa de aumento poblacional alto hasta la década de los ochenta, en las últimas tres décadas, de acuerdo con los datos de los censos de población, los municipios conurbados de la ciudad de Puebla, tales como Amozoc de Mota, San Pedro Cholula y San Martín Texmelucan, han tenido tasas de crecimiento de la población mayores que el municipio de Puebla (Gráfica 2). Esto está asociado a una mayor disponibilidad de tierra para desarrollos urbanos e industriales.

\section{Gráfica 1}

Población de los municipios en donde se localizan las ANP periurbanas

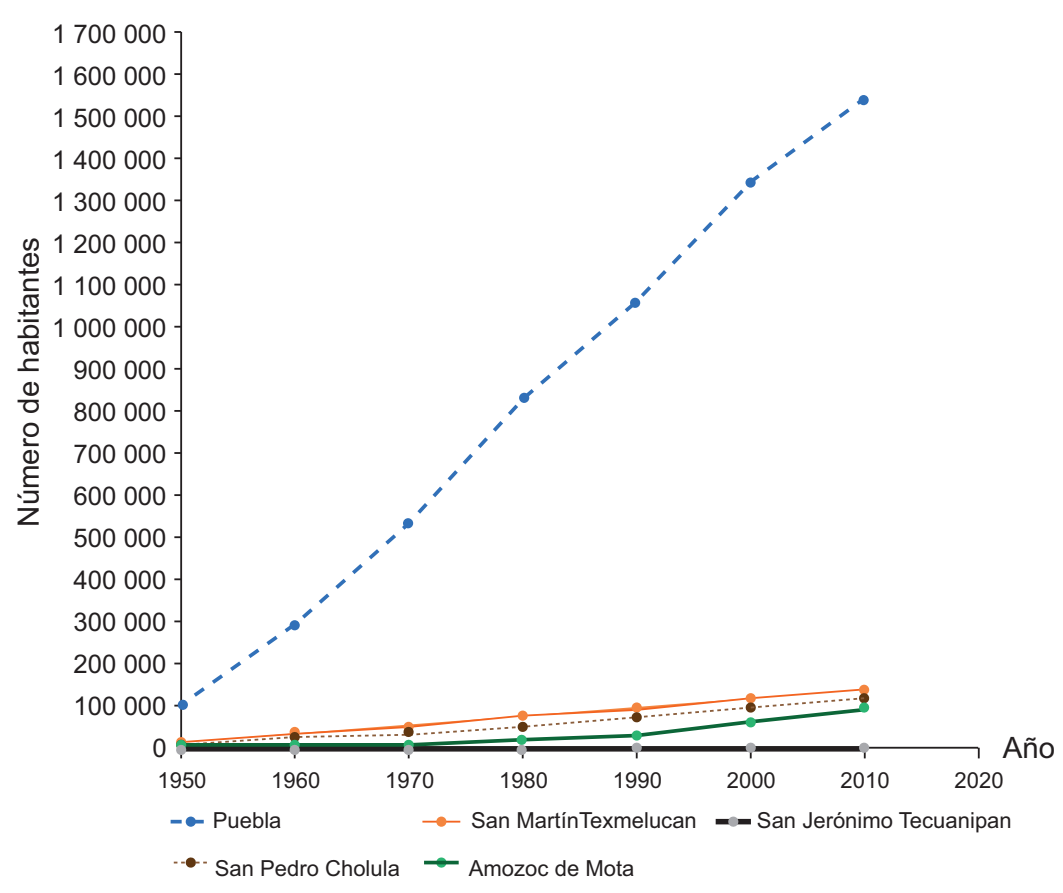

Fuente: Elaboración propia con datos de los censos de INEGI de 1950, 1960, 1970, 1980, 1990,2000 у 2010.

Estudios Demográficos y Urbanos, vol. 35, núm. 1 (103), enero-abril, 2020, pp. 51-82 http://dx.doi.org/10.24201/edu.v35i1.1828 


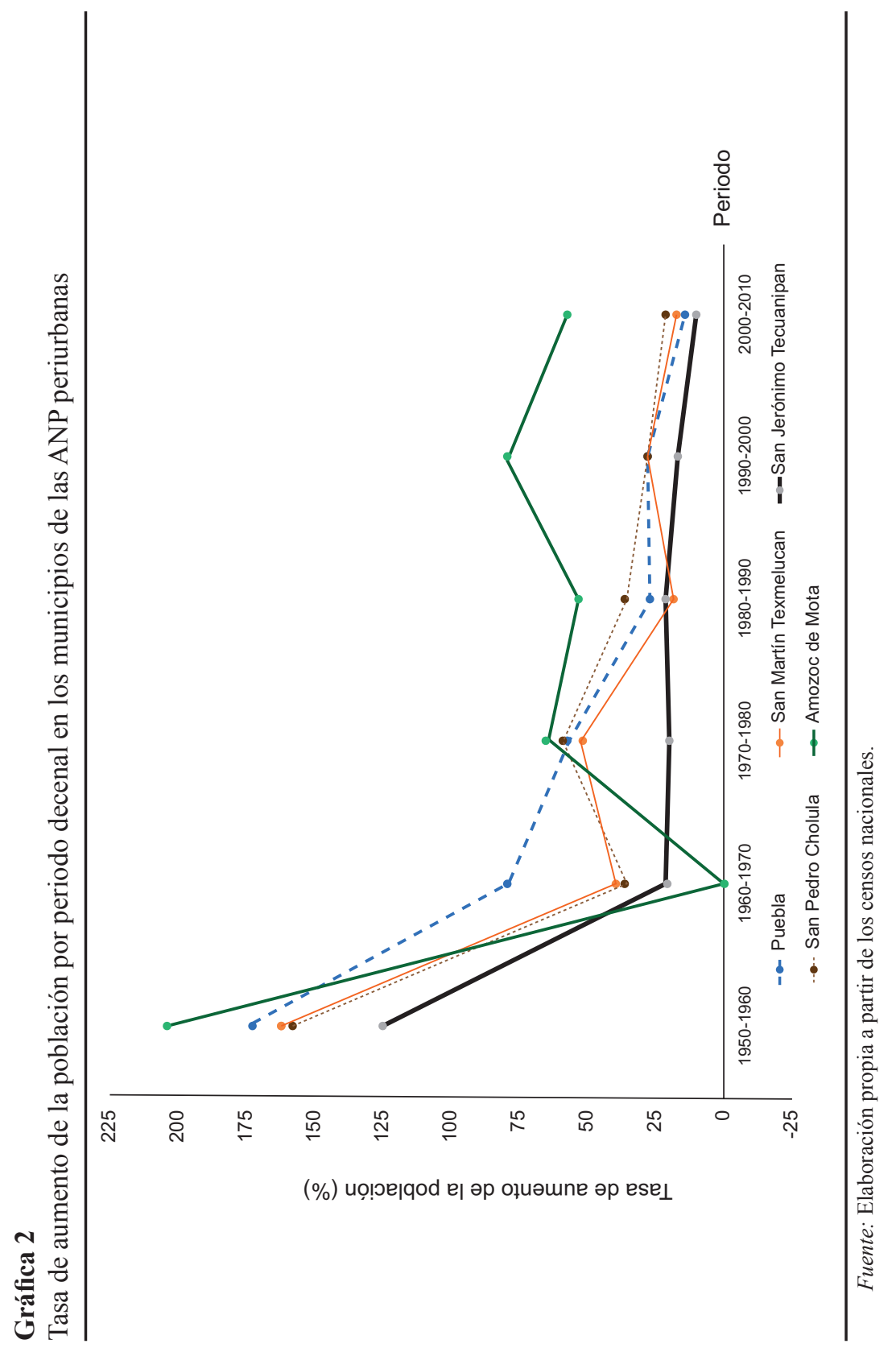


Los conflictos sociales que surgen entre los diversos actores interesados afectan negativamente a las ANP periurbanas Amalucan, Mendocinas, Tepeyac, Totolqueme y Zapotecas. El 11.8\% de los representantes gubernamentales menciona que no existen conflictos sociales, mientras que el $86.3 \%$ de los propietarios, ONG y usuarios mencionan la existencia de conflictos. En el Cerro Tepeyac los conflictos se generan por la falta de depuración del padrón de ejidatarios, las modificaciones al régimen de propiedad, el cambio de uso del suelo, la explotación de piedra y tierra (falta información a los propietarios con respecto a su extracción), y la apropiación y venta de tierras por parte de las autoridades agrarias. El Cerro Amalucan tiene conflictos derivados de la construcción de viviendas; mientras que el vandalismo y la delincuencia, características propias de las áreas urbanas, afectan el uso y la conservación de la ANP. En el Cerro Mendocinas los conflictos son ocasionados por la explotación de tierra y piedra, la depuración del padrón de ejidatarios, la delimitación territorial imprecisa y la apropiación de tierras entre los ejidatarios para construir viviendas. En el Cerro Totolqueme los conflictos se deben a la exclusión de los poseedores de la tierra en la toma de decisiones sobre la ANP, la falta de información sobre el establecimiento de antenas de comunicación y torres de electricidad (falta de distribución de los recursos económicos generados por la renta de terrenos), la poca interacción que existe entre los ejidatarios y las autoridades locales, así como por la ocupación de tierras por organizaciones políticas, como Antorcha Campesina.

En la Reserva Ecológica Zapotecas existen conflictos entre propietarios, instituciones gubernamentales, ONG, inmobiliarias y usuarios por la falta de participación e información y por la exclusión de los propietarios en el establecimiento del ANP. Otros factores detonantes son la autorización de permisos de construcción, la presencia de deportistas que realizan actividades de alto impacto que perturban y deterioran la biodiversidad, la ampliación de las áreas agrícolas, el establecimiento de antenas de telecomunicaciones, la especulación de tierras por parte de las inmobiliarias, los problemas relacionados con la tenencia de la tierra (falta de regularización de títulos de propiedad), el pastoreo, la extracción de tierra y el vandalismo. En el Parque Ecológico Flor del Bosque y en el Cerro Comalo no existen conflictos sociales; en el primero porque es administrado por el gobierno del estado, y en el segundo por ser una ANP con una superficie territorial pequeña y con vegetación de pastizal. 


\section{Factores ecológicos}

La contaminación es un factor que amenaza y afecta a las ANP periurbanas. El $92.2 \%$ del total de los entrevistados mencionó que existe algún tipo de contaminación. El 56.9\% de los entrevistados consideró que, en los cerros Amalucan, Mendocinas, Tepeyac, Totolqueme y Zapotecas, ésta se debe a residuos sólidos (en algunos con autorización de los ayuntamientos). El 5.9\% señaló la contaminación de agua y del suelo; el 29.4\% identificó la presencia de contaminación en agua, aire y suelo. El 7.8\% opinó que no existe contaminación en las ANP Parque Ecológico Flor del Bosque y en el Cerro Comalo. La contaminación del suelo es generada por el depósito clandestino de residuos sólidos (desechos orgánicos, industriales y de materiales de construcción). La contaminación del aire en el Cerro Zapotecas es ocasionada por los 4316 hornos que fabrican ladrillo, distribuidos en su entorno, los cuales emiten aproximadamente 10837.39 toneladas/año de contaminantes (Comunicación personal, Asociación Civil Xamixtli Cuacha). La contaminación del agua en el Totolqueme es provocada por el derrame de productos derivados del petróleo que, al ingresar a las líneas de riego, provoca daños a los acuíferos, además de generar erosión y degradación del suelo.

Los incendios forestales son una amenaza común. El 100\% de los informantes mencionó que se presentan anualmente y son extensivos y masivos. En su mayoría son intencionales y dañan significativamente a la vegetación. La causa principal es la quema agrícola tradicional que realizan los agricultores para la preparación de tierras de cultivo. También se relacionan con las actividades de pastoreo y con el interés por obtener el cambio del uso del suelo. El gobierno del estado, por medio de la SMRN, intenta solucionar el problema mediante el Programa de Control y Monitoreo de Incendios Forestales del Estado de Puebla (Comunicación personal, Juan Carlos Fernández Jasso, subsecretario de la SMRN).

La introducción de vegetación exótica es otra de las amenazas observadas en los recorridos de campo. Se han introducido especies exóticas en los programas de reforestación de los cerros Amalucan y Zapotecas. Las especies introducidas son: cedro blanco (Cupressus spp.), eucalipto (Eucalyptus spp.), fresno (Fraxinus uhdei), jacaranda (Jacaranda mimosifolia) y frutales, entre otras. Esto transforma el paisaje, cambia la estructura y composición de la cubierta vegetal, y lleva a la pérdida de la biodiversidad y de los ecosistemas naturales. 


\section{Factores político-institucionales}

Si para las ANP convencionales del país se tienen recursos económicos limitados, para las ANP periurbanas del estado de Puebla éstos son prácticamente inexistentes. El 86.3\% de los informantes clave afirmó que no existen recursos económicos para las ANP periurbanas y que faltan recursos humanos (administradores y técnicos capacitados) para la operación y el manejo de seis reservas ecológicas, excepto para el Parque Ecológico Flor del Bosque, que es administrado por el gobierno del estado. El 92.2\% de los propietarios, usuarios y ONG mencionaron que el gobierno estatal publica el financiamiento de algunos proyectos de conservación y protección, pero que el recurso económico es inexistente o insuficiente y sólo se realizan algunas actividades incipientes de conservación y manejo. En cambio, el $13.7 \%$ de los representantes gubernamentales considera que sí existe el recurso económico para programas de reforestación, control y vigilancia, monitoreo de incendios forestales y disminución de la tala clandestina para las siete ANP.

El Parque Estatal Flor del Bosque es un caso particular porque es administrado por la SMRN (actualmente Secretaría de Desarrollo Rural y Ordenamiento del Territorio) y cuenta con algunos proyectos para su conservación, protección, restauración y aprovechamiento. En el Cerro Tepeyac las empresas Coca Cola y Volkswagen tienen interés en realizar actividades de ecoturismo. En el Cerro Totolqueme, los ejidatarios, el gobierno municipal y las autoridades locales han desarrollado planes de turismo rural, actividades cinegéticas y agroforestería, así como proyectos arqueológicos por parte del Instituto Nacional de Antropología e Historia (INAH). En el Cerro Mendocinas se tiene la intención de desarrollar el ecoturismo, y en el Zapotecas las ONG han propuesto y establecido programas de conservación, investigación, reforestación y restauración; las universidades privadas desarrollan proyectos arqueológicos, mientras el gobierno estatal realiza algunos sobre reforestación, control y vigilancia de incendios.

Una amenaza importante para las ANP periurbanas es la falta de aplicación de la legislación vigente. Esto se relaciona con la contraposición de los objetivos de las áreas protegidas con los intereses de particulares, la indefinición de lo que es una reserva ecológica y cuestiones de tenencia de la tierra. Se encontró que $86.3 \%$ del total de entrevistados considera que no existe aplicación de las leyes y la normatividad ambiental para regular la planeación, el uso, el manejo y el aprovechamiento de las reservas ecológicas, por la falta de definición de las mismas; además, no hay coordinación entre las autoridades y los propietarios para aplicar la legislación y no existe planificación territorial adecuada en la zona conurbada de la ciudad de 
Puebla. Al respecto, la Ley de Desarrollo Urbano Sustentable del Estado de Puebla, en su artículo tercero, fracciones X, XI y XII, menciona que la protección al ambiente y la preservación del equilibrio ecológico en los centros de población será conforme a los criterios de política ambiental establecidos en la legislación aplicable. El aprovechamiento sustentable por periodos indefinidos de los recursos naturales se realizará de manera que se respete la integridad funcional y las capacidades de carga de los ecosistemas de los que forman parte dichos recursos. Las áreas protegidas de jurisdicción local están sujetas a la protección estatal, a fin de preservar ambientes naturales, salvaguardar la diversidad genética de las especies silvestres, lograr el aprovechamiento racional de los recursos naturales y mejorar la calidad del ambiente en los centros de población y sus alrededores.

Una de las amenazas más importantes para las ANP es de índole políticoinstitucional. Las instituciones gubernamentales tienen escasa información y comunicación con la sociedad en lo referente al establecimiento de las ANP periurbanas. El 54.9\% del total de los entrevistados -en su mayoría profesionistas, representantes del gobierno estatal y municipal, y ONG- tiene conocimiento sobre la definición de las ANP y su establecimiento. El 5.1\% de los propietarios y representantes municipales, locales y estatales afirmó no tener conocimiento sobre el decreto de las reservas ecológicas y la definición de qué es un ANP. El 50\% de las autoridades municipales y locales no conoce la declaratoria y qué es un ANP. Encontramos que no hay claridad por parte de las instituciones del porqué fueron decretadas como reservas ecológicas y del objetivo de las mismas. Se observa la falta de continuidad y disponibilidad de las dependencias gubernamentales responsables para diseñar y establecer nuevas políticas ambientales y marcos legales que permitan administrar y manejar en forma adecuada a las ANP. Además, éstas no han sido consideradas en los Planes de Desarrollo del estado ni de los municipios.

\section{Discusión}

Las ANP periurbanas del estado de Puebla realmente no están operando como estrategia de planificación territorial y conservación debido a diversos factores económicos, sociales, ecológicos y político-institucionales. Se observa que las ANP periurbanas presentan similitud en varias de sus características. Dos son de competencia estatal y cinco -que cuentan con una superficie pequeña-, de los ayuntamientos municipales. Actualmente todas las áreas protegidas, aunque conservan componentes de los ecosistemas naturales, tienen una baja representatividad de la biodiversidad característica de los 
ecosistemas originales, lo que genera controversia sobre qué tanto son comparables con las ANP convencionales. El origen mismo de las áreas protegidas periurbanas del estado de Puebla explica parte de su situación actual. Desde el punto de vista gubernamental, su establecimiento se realizó con una planeación adecuada (Sedurbecop, 2001). Sin embargo, aunque se tomó la figura de las ANP convencionales como justificación y estrategia de conservación, los factores del desarrollo urbano -como la presión de los desarrollos habitacionales y de los servicios comerciales y recreativos- las convirtieron realmente en reservas territoriales; cuando se requiera se utilizarán para esos fines. Por ejemplo, actualmente el gobierno del estado de Puebla busca convertir el Cerro Amalucan en un parque recreativo, mientras que un sector importante de la sociedad pugna porque mantenga su objetivo original de área verde (La Jornada de Oriente, 2017).

La falta de delimitación precisa de las ANP periurbanas es determinante para su manejo y para mantener su integridad territorial. Si bien cuando se decretaron las ANP el gobierno del estado y los municipios pudieron tener limitaciones técnicas para hacer una delimitación cartográfica precisa, no se observa interés por corregir actualmente esta situación. Para cumplir con los objetivos iniciales, como el de contribuir al desarrollo urbano y la conservación del medio ambiente mediante la creación de áreas verdes y la reforestación, se requiere una planeación espacial en un territorio bien delimitado. Esto también es necesario para un programa eficiente de monitoreo y supervisión.

Si el objetivo principal real de la creación de las ANP periurbanas fue, como menciona el Plan Estatal de Desarrollo 1993-1999, establecer características y límites de crecimiento urbano en la zona conurbada de la ciudad de Puebla (Gobierno del Estado de Puebla, 1993), tampoco se ha tenido éxito. Los factores socioeconómicos y ecológicos -tanto los generados en los centros urbanos adyacentes, como en las comunidades que utilizan las ANP, rurales y semirrurales- han neutralizado las escasas acciones de conservación y gestión de las áreas protegidas.

Las tierras de las ANP periurbanas, al igual que cualquier zona del área metropolitana de la ciudad de Puebla, tienen un valor comercial que hace difícil convencer a los propietarios originales de que no las vendan. Esta tendencia es común en las áreas protegidas urbanas y periurbanas. En la Ciudad de México, en la alcaldía Tlalpan los ejidatarios de manera individual compran o venden áreas de conservación (Ruíz-Gómez, 2006, pp. 95-97). En la alcaldía Tláhuac, la expansión urbana ha ocupado los suelos de conservación de manera irregular (San Miguel, 2010, p. 163). Mientras que, en la alcaldía Xochimilco, tales suelos son ocupados paulatinamente por asentamientos irregulares (Wigle, 2014, p. 580). 
También es complicado evitar que los propietarios originales de la tierra de las ANP periurbanas renuncien, sin ningún incentivo económico, a seguir realizando sus actividades productivas y extractivas. Si bien la ciudad de Puebla genera con frecuencia opciones de empleo de fin de semana para los agricultores de la región, es un factor que reduce la actividad agrícola. Además, la disponibilidad de tierra para el cultivo también es menor y las ANP periurbanas son utilizadas para generar ingresos para el sustento familiar, lo que incrementa el deterioro de los ecosistemas de las ANP y la transformación de su paisaje. Situación similar se presenta por la extracción de piedra, tierra, flora y fauna, lo que crea una situación complicada desde el punto de vista de las políticas públicas de conservación. Por un lado, aunque investigaciones realizadas en otras ANP mencionan que el aprovechamiento de la vida silvestre en estas áreas proporciona beneficios a un número reducido de individuos y puede afectar de manera negativa e irreversible a la biodiversidad (Mayaka, 2002; 2008), es complicado diferenciar los efectos del manejo de la ANP de los atribuidos a otros factores (Ferraro y Hanauer, 2015, pp. 9-10). Por otro lado, los propietarios mencionan que tienen el derecho legítimo al uso y venta de la tierra y de sus recursos porque las ANP formaban parte de su territorio antes de que se declararan áreas protegidas, aunque el establecimiento de las ANP implica un cambio en la posesión de la tierra y sus recursos (West, Igoe y Brockington, 2006, p. 257). Para los propietarios, la tierra y sus recursos naturales son parte de su patrimonio y los perciben como valores de uso directo, mientras los servicios ambientales que las áreas protegidas proveen son de interés para la sociedad en general (Stolton et al., 2015, pp. 156-158).

El establecimiento de las ANP periurbanas del estado de Puebla ha generado conflictos que sólo son atendidos por las instituciones gubernamentales cuando son publicados en la prensa o cuando algunos actores presionan para su solución. Es notorio que los diversos actores tienen objetivos contrapuestos. Para las instituciones el objetivo principal es, por lo menos en el discurso, la planificación territorial y la conservación de las reservas ecológicas. Los propietarios, por su parte, aspiran al desarrollo de las poblaciones que habitan en torno a las ANP periurbanas, lo que incluye el continuar con sus actividades productivas tradicionales. Las organizaciones no gubernamentales $(\mathrm{ONG})$ interesadas en la conservación exigen a las instituciones gubernamentales el apego a la declaratoria con el fin de evitar el cambio de uso de suelo. Mientras que los usuarios externos a las ANP requieren espacios para actividades deportivas, recreativas y de turismo natural, lo que impide la homogeneidad de intereses entre los propietarios y los actores sociales interesados. La contraposición de objetivos ha sido re- 
portada para otras ANP, como la Reserva de la Biosfera Mariposa Monarca, donde se tienen conflictos de intereses entre los mismos ejidatarios por la explotación y el aprovechamiento de los recursos naturales; así como entre los propietarios y los usuarios con respecto a la vida silvestre porque algunos desean utilizar los recursos naturales, mientras que otros promueven su protección y conservación (Brenner, 2006, p. 261). En estos conflictos generalmente quienes pierden son los poseedores originales de la tierra y los ecosistemas, ya que la opción preferida es el desalojo y la violación de sus derechos, con la consecuente degradación de las ANP (Colchester, 2004, p. 146; West, Igoe y Brockington, 2006, pp. 257-260).

Aunque la presión de los factores ecológicos sobre la conservación de los ecosistemas de las ANP periurbanas del estado de Puebla es menor comparada con la ejercida por los factores socioeconómicos, hay cierta incidencia. Pero el gobierno estatal y los gobiernos municipales no tienen programas para su control. El gobierno del estado reporta que tiene un programa de incendios forestales, pero no ha logrado la prevención y el control de incendios debido principalmente a la falta de recursos humanos y económicos y a la falta de cooperación de las autoridades locales y municipales. Asimismo, no hay un programa para atender el vertido de desechos sólidos en el territorio de las ANP. Esto es consecuencia, en parte, de la falta de planes de manejo de las áreas protegidas, elemento esencial de una estrategia de conservación.

En el manejo de las ANP periurbanas tampoco se ha dado importancia a la prevención en la introducción de especies exóticas. Esto plantea una visión diferente al concepto tradicional de un área natural protegida, en donde se pone énfasis en el mantener la biodiversidad presente y en el funcionamiento y estructura del ecosistema nativo, previniendo su deterioro por factores como las especies exóticas (Van Driesche y Center, 2015, p. 561). La introducción de especies con impacto severo, como el eucalipto, origina el desplazamiento de la vegetación y fauna nativa, el cambio en la composición y estructura del ecosistema, la pérdida de la biodiversidad y la transformación del hábitat y del paisaje.

Los factores político-institucionales son determinantes en la gestión de las ANP periurbanas del estado de Puebla. Los programas y proyectos para la conservación de éstas áreas son insuficientes, y los recursos económicos y humanos para su gestión son escasos y dirigidos a actividades muy localizadas, no integradas en objetivos y metas integrales para el manejo de las ANP. El análisis de la gestión de las ANP periurbanas mostró que, desde su creación, la prioridad en su gestión y en los recursos económicos destinados a ellas depende mucho de las políticas de los gobiernos estatal 
y municipal en turno, a diferencia de la gestión de las ANP federales -bajo la responsabilidad de la Comisión Nacional de Áreas Naturales Protegidas-. Aunque el problema del financiamiento es notable en las áreas naturales protegidas federales, se acentúa en las estatales y las municipales. El escaso financiamiento es común en las áreas protegidas de Latinoamérica (Hardner, 2008, p. 1).

La falta de aplicación de la legislación vigente para mantener la integridad territorial y regular el uso y aprovechamiento de los recursos naturales de las ANP periurbanas del estado de Puebla hace inviable una estrategia de conservación basada en un enfoque de comando y control, ya que ello implica que las normas sean codificadas en regulaciones y reglas administrativas, políticas públicas y leyes (Manning y Krymkowski, 2010, p. 12), situación no presente en las ANP estudiadas. Falta coordinación y responsabilidad de las autoridades gubernamentales federales, estatales y municipales, sin que se observe voluntad de superarla. Por otro lado, en la situación actual tampoco se evidencia algún interés en los diversos actores por desarrollar vías de gestión de las ANP con un enfoque participativo, voluntario y por consenso.

\section{Conclusiones}

Las ANP periurbanas en el estado de Puebla, México, fueron promovidas por el gobierno estatal con fines de planeación territorial y no para una planificación de conservación de la biodiversidad, ya que no se consideró la representatividad de los ecosistemas, y su gestión no es congruente con la gestión convencional de un ANP. Su situación actual se caracteriza por la falta de una delimitación espacial precisa, la inexistencia de planes de manejo, la pérdida territorial y el deterioro de los recursos naturales, así como por conflictos sociales en torno a las regulaciones de las ANP y un marcado desinterés de las instituciones gubernamentales estatales, municipales y locales para la gestión de estas áreas.

La comercialización de las tierras de las ANP, las actividades agrícolas, pecuarias y de extracción de recursos naturales, así como la contraposición de los intereses de los involucrados y los factores ecológicos como los incendios, la erosión y la contaminación, son factores negativos que hacen inviable el funcionamiento de las ANP periurbanas del estado de Puebla. Esto es acentuado por factores político-administrativos, como el desinterés de las instituciones gubernamentales y locales por su conservación, la falta de recursos económicos y humanos para su gestión, y la no aplicación de la 
normatividad para regular la venta de tierras, las actividades y el uso de recursos naturales en las áreas protegidas.

Para hacer funcionales las ANP periurbanas del estado se requiere una verdadera disposición para enfrentar los grandes retos que representa su manejo, como es el detener la pérdida territorial de las mismas. Se requiere replantear su marco legal y la política ambiental estatal para que estén acordes a las necesidades actuales de las ANP periurbanas. Para esto, las instituciones responsables de las ANP deben ejercer una función rectora y considerar a los diferentes actores interesados, con el propósito de fomentar la participación e inclusión social para lograr el adecuado uso, manejo y aprovechamiento de aquéllas en el bienestar social, como lo menciona su decreto. Se requiere fomentar la apropiación de las ANP como capital natural, no sólo en términos económicos y de conservación, sino también como espacios naturales productores y generadores de bienes y servicios ambientales; de tal manera que las comunidades locales y los propietarios de las ANP asimilen y propicien el equilibrio entre lo social, lo económico y lo ecológico para mejorar su nivel de vida y mitigar el deterioro de las ANP periurbanas que forman parte de la zona conurbada de la ciudad de Puebla.

\section{Bibliografía}

Amaya, C. A. (2005). El ecosistema urbano: simbiosis espacial entre lo natural y lo artificial. Revista Forestal Latinoamericana, 37, 1-16. Recuperado de http://www.saber.ula.ve/bitstream/handle/123456789/24099/ articulo1.pdf;jsessionid=F2709A76B18CEA80BB732E9FE9E7CB07? sequence $=2$

Bezaury-Creel, J. y Gutiérrez, D. (2009). Áreas naturales protegidas y desarrollo social en México. En R. Dirzo, R. González e I. J. March (comps.), Capital natural de México. Vol. 2: Estado de conservación y tendencias de cambio (pp. 352-431). Ciudad de México: Comisión Nacional para el Conocimiento y Uso de la Biodiversidad

Brenner, L. (2006). Áreas naturales protegidas y ecoturismo: el caso de la Reserva de la Biosfera Mariposa Monarca, México. Relaciones. Estudios de Historia y Sociedad, 27(105), 237-265. Recuperado de https://www. redalyc.org/articulo.oa?id $=13710508$

Cedillo, O. L., Rivas, M. A. y Rodríguez, F. N. (2007). El área natural protegida sujeta a conservación ecológica "Sierra de Guadalupe". Revista Sistemas Ambientales, 1(1), 1-14. Recuperado de https://es.scribd.com/ document/195778540/Sierra-de-Guadalupe 
Colchester, M. (2004). Conservation policy and indigenous peoples. Environmental Science and Policy, 7(3), 145-153. Recuperado de https:// www.sciencedirect.com/science/article/pii/S1462901104000322

Conabio. (2015). Áreas naturales protegidas estatales, municipales, ejidales y privadas de México 2015. Ciudad de México: Comisión Nacional para el Conocimiento y Uso de la Biodiversidad. Recuperado de http://www. conabio.gob.mx/informacion/gis/

Conanp. (2017). Áreas naturales protegidas decretadas. Ciudad de México: Comisión Nacional de Áreas Naturales Protegidas. Recuperado de http:// sig.conanp.gob.mx/website/pagsig/datos anp.htm

Diario Oficial de la Federación. (2012). Ley General del Equilibrio Ecológico y la Protección al Ambiente. Última reforma DOF 04-06-2012. Diario Oficial de la Federación. Ciudad de México: Recuperado de http://www.diputados.gob.mx/LeyesBiblio/ref/lgeepa/LGEEPA_ ref25_04jun12.pdf

Douglas, I. (2006). Peri-urban ecosystems and societies: Transitional zones and contrasting values. En D. McGregor, D. Simon y D. Thompson (eds.), The peri-urban interface (pp.18-29). Londres: Earthscan.

Fernández, A., Vázquez, A., Uribe, F., Bustillos, J., Aguilar, H., Juárez, M., ... Vera, J. J. (2004). Ecoturismo y desarrollo económico sustentable en la alcaldía La Magdalena Contreras, Distrito Federal. Gaceta Ecológica, 70, 67-70. Recuperado de https://www.redalyc.org/articulo.oa?id=53907006 Fernández, A., Uribe, F., Ramírez del Razo, I., Apolinar, B. y Vázquez, A. (2002). Evaluación del avance de la mancha urbana sobre el área natural protegida de la Cañada de los Dinamos. Gaceta Ecológica, 62, 56-67. Recuperado de https://www.redalyc.org/pdf/539/53906205.pdf

Ferraro, P. J. y Hanauer, M. (2015). Through what mechanisms do protected areas affect environmental and social outcomes? Philosophical Transactions of the Royal Society B: Biological Sciences, 370(1681), 1-14. Recuperado de https://royalsocietypublishing.org/doi/10.1098/rstb.2014. 0267

García, E. (1973). Modificaciones al sistema de clasificación climática de Köppen para adaptarlo a las condiciones de la República Mexicana. Ciudad de México: UNAM, Instituto de Geografía.

Gobierno del Estado de Puebla. (1976). Plan de Desarrollo del Estado de Puebla 1976-1979. Puebla: Gobierno del Estado de Puebla.

Gobierno del Estado de Puebla. (1993). Plan de Desarrollo del Estado de Puebla 1993-1999. Puebla: Gobierno del Estado de Puebla.

Gobierno del Estado de Puebla. (1999). Plan Estatal de Desarrollo Urbano Sustentable. Puebla: Sedueep. 
Gobierno del Estado de Puebla. (2001). Actualización e implementación del Proyecto de Ordenamiento Ecológico para la Región Centro-Poniente del Estado de Puebla (primera fase). Puebla: Gobierno del Estado de Puebla, Secretaría de Desarrollo Urbano Ecología y Obras Públicas.

Güneralp, B. y Seto, K. C. (2013). Futures of global urban expansion: Uncertainties and implications for biodiversity conservation. Environmental Research Letters, 8(1), 1-10. Recuperado de http://iopscience.iop. org/article/10.1088/1748-9326/8/1/014025/meta

Hardner, J. (2008). The problem of financing protected areas in the AndesAmazon region. Ponencia presentada en la conferencia Economics and Conservation in the Tropics: A Strategic Dialogue, 31 de enero. Recuperado de https://www.conservation-strategy.org/en/publication/pro blem-financing-protected-areas-andes-amazon-region\#.XFSX3FxKiUk INEGI. (1950). VII Censo General de Población 1950. México: Instituto Nacional de Estadística y Geografía: Recuperado de http://www.beta. inegi.org.mx/programas/ccpv/1950/default.html

INEGI. (1960). VIII Censo General de Población, 1960. México: Instituto Nacional de Estadística y Geografía: Recuperado de http://www.beta. inegi.org.mx/programas/ccpv/1960/default.html

INEGI. (1970). IX Censo General de Población, 1970. México: Instituto Nacional de Estadística y Geografía: Recuperado de http://www.beta. inegi.org.mx/programas/ccpv/1970/default.html

INEGI. (1980). X Censo General de Población y Vivienda, 1980. México: Instituto Nacional de Estadística y Geografía: Recuperado de http:// www.beta.inegi.org.mx/programas/ccpv/1980/default.html

INEGI. (1990). XI Censo General de Población y Vivienda, 1990. México: Instituto Nacional de Estadística y Geografía: Recuperado de http:// www.beta.inegi.org.mx/programas/ccpv/1990/default.html

INEGI. (2000). XII Censo General de Población y Vivienda, 2000. México: Instituto Nacional de Estadística y Geografía: Recuperado de http:// www.beta.inegi.org.mx/programas/ccpv/2000/default.html

INEGI. (2001). Cartas topográficas del Estado de Puebla E14B32, E14B42, E14B43, E14B52 y E14B53, escala 1:50 000. México, Instituto Nacional de Estadística y Geografía. Recuperado de http://www.inegi.org.mx/ geo/contenidos/topografia/default.aspx

INEGI. (2010). Censo de Población y Vivienda, 2010. México: Instituto Nacional de Estadística y Geografía: Recuperado de http://www.beta. inegi.org.mx/programas/ccpv/2010/default.html

Intolerancia. (2016). Flor del Bosque: de reserva ecológica a parque recrea- 
tivo. Intolerancia, Puebla, 18 de septiembre. Recuperado de http://into leranciadiario.com/detalle_noticia/147874/especiales/flor-del-bosquede-reserva-ecologica-a-parque-recreativo

Knuth, L. (2005). Legal and institutional aspects of urban and peri-urban forestry and greening (Documento de Investigación, núm. 88). Roma, Italia: FAO Legislative Study. Recuperado de http://www.fao.org/filead $\mathrm{min} /$ user_upload/legal/docs/ls88-e.pdf

La Jornada de Oriente. (2017). Vecinos que han reforestado el Cerro de Amalucan buscan erigir un bosque; el gobierno, un parque. La Jornada de Oriente. Puebla, 10 de julio. Recuperado de http://www.lajornada deoriente.com.mx/2017/07/10/vecinos-reforestado-cerro-amalucanbuscan-erigir-bosque-gobierno-parque/

Liu, J., Linderman, M., Ouyang, Z., An, L., Yang, J. y Zhang, H. (2001). Ecological degradation in protected areas: The case of Wolong nature reserve for giant pandas. Science, 292(5514), 98-101. Recuperado de http://science.sciencemag.org/content/292/5514/98

Manea, G., Matei, E., Vijulie, I., Tîrla, L., Cuculici, R., Cocos, O. y Tiscovschi, A. (2016). Arguments for integrative management of protected areas in the cities. Case study in Bucharest city. Procedia Environmental Sciences, 32, 80-96. Recuperado de https://www.sciencedirect.com/ science/article/pii/S1878029616001407

Manning, R. E. y Krymkowski, D. H. (2010). Standards of quality for parks and protected areas. Applying normative theory and methods in U.S. national parks. International Journal of Sociology, 40(3), 11-29. Recuperado de https://www.jstor.org/stable/20788552?seq=1\#metadata_info_ tab contents

Manolaki, P. y Vogiatzakis, I. N. (2017). Ecosystem services in a peri-urban protected area in Cyprus: A rapid appraisal. Nature Conservation, 22, 129-146. Recuperado de https://natureconservation.pensoft.net/arti cle/13840/

Mayaka, T. B. (2002). Wildlife co-management in the Bénoué National ParkComplex, Cameroon: A bumpy road to institutional development. World Development, 30(11), 2001-2016. Recuperado de https://www.science direct.com/science/article/pii/S0305750X02001110

McDonal, R. I., Marcotullio, P. J. y Güneralp, B. (2013). Urbanization and global trends in biodiversity and ecosystem services. En T. Elmqvist, M. Fragkias, J. Güneralp, P. J. Marcotullio, R. I. McDonald, S. Parnell, ... C. Wilkinson (eds.), Urbanization, biodiversity and ecosystem services: Challenges and opportunities (pp. 31-52), Nueva York, NY: Springer Open. 
Palomo, I., Montes, C., Martín-López, B., González, J. A., García-Llorante, M., Alcorlo, P. y García, M. R. (2014). Incorporating the social-ecological approach in protected areas in the Anthropocene. BioScience, 64(3), 181-191. Recuperado de https://academic.oup.com/bioscience/arti cle/64/3/181/224408

Pauchard, A., Aguayo, M., Peña, E. y Urrutia, R. (2006). Multiple effects of urbanization on the biodiversity of developing countries: The case of a fast-growing metropolitan area (Concepción, Chile). Biological Conservation, 127(3), 272-281. Recuperado de https://www.sciencedirect. com/science/article/pii/S0006320705003587

Periódico Oficial del Estado de Puebla. (1985). Declaratoria de utilidad pública y beneficio social para la creación del parque ecológico recreativo "General Lázaro Cárdenas" en el predio denominado "Flor del Bosque", del municipio de Amozoc, Puebla. Periódico Oficial de Estado de Puebla, 24 de diciembre.

Periódico Oficial del Estado de Puebla. (1994). Declaratoria de reservas, destinos y usos de predios y áreas territoriales del Programa Regional de Ordenamiento Territorial de la zona Centro-Poniente del Estado de Puebla. Periódico Oficial del Estado de Puebla, 8 de abril.

Periódico Oficial del Estado de Puebla. (2008). Declaratoria del ejecutivo del Estado por el que se declara Área Natural Protegida, con carácter de Jurisdicción Estatal, la zona denominada "Cerro Zapotecas", ubicada en el Municipio de San Pedro Cholula. Periódico Oficial del Estado de Puebla, 26 de noviembre.

Phillips, A. (2003). Turning ideas on their head: The new paradigm for protected areas. The George Wright Forum, 20(2), 8-32. Recuperado de https://www.jstor.org/stable/43599027?seq=1\#page_scan_tab_contents

Ruíz-Gómez, M. (2006). El crecimiento de los asentamientos irregulares en áreas protegidas. La alcaldía Tlalpan. Investigaciones Geográficas, Boletín del Instituto de Geografía, UNAM, 60, 83-109. Recuperado de http://www.scielo.org.mx/pdf/igeo/n60/n60a6.pdf

San Miguel, R. T. (2010). La expansión urbana en suelo de conservación en la delegación Tláhuac, DF, México (Tesis de maestría en Población y Desarrollo, Flacso México). Recuperado de http://repositorio.flacsoan des.edu.ec/xmlui/bitstream/handle/10469/2819/TFLACSO-03-2010RTS MV.pdf? sequence $=1$ \&isAllowed $=\mathrm{y}$

Sedueep. (1999). Plan Estatal de Desarrollo Urbano Sustentable. Gobierno del Estado de Puebla, Secretaría de Desarrollo Urbano y Ecología del Estado de Puebla. 
Sedurbecop. (2001). Sistema de áreas naturales de la región Centro-Poniente de estado de Puebla. Puebla: Gobierno del Estado de Puebla, Secretaría de Desarrollo Urbano, Ecología y Obras Públicas.

SMNR. (2005). Programa de Manejo Integral del Parque Estatal Flor del Bosque. Puebla: Gobierno del Estado de Puebla, Secretaría de Medio Ambiente y Recursos Naturales.

Stolton, S., Dudley, N., Avcioglu Cokcaliskan, B., Hunter, D., Ivanic, K., Kanga, E., ... Waithaka, J. (2015). Values and benefits of protected areas. En G. L. Worboys, M. Lockwood, A. Kothari, S. Feary e I. Pulsford (eds.), Protected area governance and management (pp.145-168). Canberra, Australia: ANU Press.

Trzyna, T. (2007). Global urbanization and protected areas. Sacramento, CA: California Institute of Public Affairs.

Van Driesche, R. y Center, T. (2015). Biological control of invasive plants in protected areas. En L. C. Foxcroft, P. Pysek, D. M. Richardson y P. Genovesi (coords.), Plant invasions in protected areas. Patterns, problems and challenges (pp. 561-597). Londres: Springer.

Vargas, M. F. (1997). Parques nacionales de México. Ciudad de México: Secretaría de Medio Ambiente, Recursos Naturales y Pesca / Instituto Nacional de Ecología.

West, P., Igoe, J. y Brockington, D. (2006). Parks and peoples: The social impact of protected areas. Annual Review of Anthropology, 35, 251-277. Recuperado de https://www.annualreviews.org/doi/10.1146/annurev. anthro.35.081705.123308

Wigle, J. (2014). The graying of green zones: Spatial governance and irregular settlement in Xochimilco, Mexico City. International Journal of Urban and Regional Research, 38(2), 573-589. Recuperado de https:// onlinelibrary.wiley.com/doi/full/10.1111/1468-2427.12019

\section{Acerca de los autores}

Margarita Tlapa Almonte es doctora en Estrategias de Desarrollo Agrícola Regional por el Colegio de Postgraduados, campus Puebla; cuenta con posdoctorado en Manejo de Agroecosistemas, por la Benemérita Universidad Autónoma de Puebla (BUAP); es maestra en Ciencias en Biología Ambiental, por la Universidad Nacional Autónoma de México, y química farmacobióloga por la BUAP. Actualmente se desempeña como investigadora en Reserva Ecológica Zapotecas, A.C. (REZAC) y está afiliada a Sociedades en Red (Socir). También colabora con la Secretaría de Cultura del Gobierno 
del Estado de Puebla y la UNESCO. Su línea de investigación es recursos naturales y cultura, en temas de diagnósticos socioambientales, florística, estrategias para la conservación de la biodiversidad, patrimonio biocultural y planificación territorial. Dentro de sus logros sobresale su contribución a la primera declaratoria estatal oficial del Área Natural Protegida Cerro Zapotecas y la obtención del segundo lugar, en presentación de ponencia, en el VII Congreso Nacional de la Comisión Nacional de Áreas Naturales Protegidas (2009). Además, fue dos veces ganadora distinguida del Programa de Apoyo a las Culturas Municipales y Comunitarias, del Consejo Estatal para la Cultura y las Artes. ORCID: https://orcid.org/0000-0001-5517-3927

Algunas de sus publicaciones son:

Tlapa, M., Bustamante, A., Vargas, S., Ramírez, B. y Cervantes, V. (2009).

Situación actual de las áreas naturales protegidas periurbanas del Valle de Puebla, México. En R. Reyes, L. M. Tenorio y R. S. Tapia (coords.), Perspectivas del patrimonio natural edificado (pp. 35-59). Puebla: Benemérita Universidad Autónoma de Puebla.

Tlapa, M. y Zamora, J. (2009). Los cuetlas: una comida tradicional en la feria de San Pedro Cholula. Puebla: Programa de Apoyo a las Culturas Municipales y Comunitarias.

Ángel Bustamante González es doctor en Manejo de Cuencas, por la Universidad de Arizona, Estados Unidos; maestro en Ciencias en Edafología, por el Colegio de Postgraduados, campus Montecillo; e Ingeniero Agrónomo Especialista en Suelos, por la Universidad Autónoma Chapingo. Es profesor investigador en el Colegio de Postgraduados, campus Puebla. Su línea de investigación es medio ambiente y recursos naturales. Es miembro del Sistema Nacional de Investigadores, nivel I. ORCID: http://orcid.org/00000002-0727-9505

Algunas de sus publicaciones son:

Mora-Carvajal, M. J., Bustamante-González, A., Cajuste, L., Vargas, S., Cruz, G. M. y Ramírez-Juárez, J. (2019). Payments for hydrologic environmental services and forest cover dynamics in the Iztaccíhuatl-Popocatépetl region, Puebla. Acta Agronómica, 68(2), 84-91. Recuperado de https://revistas.unal.edu.co/index.php/acta_agronomica/article/view /66291/70882

Mena, I., Bustamante, G., Vargas, L., Olvera, J. I. y Méndez, J. A. (2017). Evaluación de la condición ecológica del río Zahuapan. Revista Internacional de Contaminación Ambiental, 33(1), 7-19. Recuperado de http:// www.scielo.org.mx/pdf/rica/v33n1/0188-4999-rica-33-01-00007.pdf

Bustamante-González, A., Galindo-De Jesús, G., Jaramillo-Villanueva, J. L. 
y Vargas-López, S. (2016). Percepción de la contaminación del río Tlapaneco por la población ribereña. Agricultura, Sociedad y Desarrollo, 13(1), 47-62. Recuperado de http://www.scielo.org.mx/scielo.php? script $=$ sci_abstract\&pid=S1870-54722016000100047\&lng=en\&nrm $=\mathrm{i}$ so\&tlng $=\mathrm{es}$

Samuel Vargas López es doctor en Producción Animal, por la Universidad de Córdoba, España. Es profesor investigador del Colegio de Postgraduados, campus Puebla. Su experiencia profesional y de investigación se ha orientado a la producción y gestión sostenible de la ganadería en regiones de alta marginación. Ha colaborado en proyectos en ganadería agroecológica, conservación del ambiente y recursos naturales de zonas indígenas. Como parte de su trabajo, el Colegio de Postgraduados le ha otorgado durante diez años el estímulo de los 100 académicos distinguidos del Colegio de Postgraduados. ORCID: http://orcid.org/0000-0002-8303-3128

Sus publicaciones más recientes son:

Jaramillo, J. L., Vargas, S. y Rojas, L. A. (2018). Valoración contingente y disponibilidad a pagar por atributos intangibles en carne de bovino. Revista Mexicana de Ciencias Pecuarias, 9(1), 14-31. Recuperado de https://cienciaspecuarias.inifap.gob.mx/index.php/Pecuarias/article/ view/4376

Vargas-López, S., Bustamante-González, A., Vargas-Monter, J., HernándezZepeda, J. S., Vázquez-Martínez, I. y Calderón-Sánchez, F. (2017). Diversidad y prácticas de crianza de animales domésticos en traspatios de comunidades indígenas en Guerrero, México. Revista Agroproductividad, 10(7), 15-20. Recuperado de http://revista-agroproductividad. org/index.php/agroproductividad/article/view/1050

Neri, M., Bustamante, A., Vargas, S. y Guerrero, J. D. (2015). Representatividad ecológica de las áreas naturales protegidas del estado de Puebla, México. Ecología Aplicada, 14(2), 87-93. Recuperado de https://www. redalyc.org/articulo.oa?id $=34143179001$

Benito Ramírez Valverde es doctor y maestro en Estudios Latinoamericanos por la Universidad de Tulane, Estados Unidos; maestro en Ciencias en Estadística por el Colegio de Postgraduados; e ingeniero agrónomo, especialista en Fitotecnia, por la Universidad Autónoma Chapingo. Es profesor investigador en el Colegio de Postgraduados, campus Puebla. Su línea de investigación es desarrollo rural y pobreza rural. Es miembro de la Academia Mexicana de Ciencias. Pertenece al Sistema Nacional de Investigadores, nivel II. ORCID: http://orcid.org/0000-0003-2482-5667 
Algunas de sus publicaciones recientes son:

Bastidas-Orrego, L. M., Ramírez-Valverde, B., Cesín Vargas, A., Juárez Sánchez, J. P., Martínez Carrera, D. y Vaquera Huerta, H. (2019). Las comunidades de la Sierra Norte de Puebla, México, frente a los megaproyectos de minería. Revista de El Colegio de San Luis, 9(18), 183-207. Recuperado de http://revista.colsan.edu.mx/index.php/COLSAN/article/ view/899/pdf

Cardeña, I., Ramírez-Valverde, B., Juárez, J., De la Peña, A. y Cruz, A. (2019). Campesinos y sistema de producción de café ante el problema de la roya en el municipio de Hueytamalco, Puebla, México. Espacio abierto: Cuaderno Venezolano de Sociología, 28(2), 59-78. Recuperado de https:// dialnet.unirioja.es/servlet/articulo?codigo $=6998550$

Torres-Solís, M. y Ramírez-Valverde, B. (2019). Buen vivir y vivir bien: alternativas al desarrollo en Latinoamérica. Revista de Estudios Latinoamericanos, 69, 71-97. Recuperado de http://www.revistadeestlat. unam.mx/index.php/latino/article/view/57106/50899

Gustavo Manuel Cruz Bello es doctor en Estudio de los Recursos Naturales Renovables, por la Universidad de Arizona, Estados Unidos; maestro en Ecología y licenciado en Biología, por la Universidad Nacional Autónoma de México. Actualmente es profesor-investigador en el Departamento de Ciencias Sociales de la Universidad Autónoma Metropolitana, unidad Cuajimalpa. Sus líneas de investigación son: análisis espacial de los socioecosistemas, ordenamiento ecológico del territorio, y vulnerabilidad al cambio climático. Es miembro del Sistema Nacional de Investigadores, nivel I. ORCID: https://orcid.org/0000-0001-9118-6565

Entre sus publicaciones recientes se encuentran:

Alfie, M. y Cruz-Bello, G. M. (2018). Living with risk: Climate change and vulnerability. Community perceptions in peri-urban areas of La Paz City, Mexico. Sociedad y Ambiente, 19, 109-136. Recuperado de http://revistas. ecosur.mx/sociedadyambiente/index.php/sya/article/view/1936/1772

Cruz-Bello, G. M., Alfie-Cohen, M., Morales-Zaragoza, N. A., Larralde-Corona, A. H. y Reyes Pérez, J. (2018). Flood vulnerability reduction, using a partial participatory GIS approach. A study case in Baja California Sur, Mexico. The International Archives of the Photogrammetry, remote sensing and spatial information sciences, 42(3), 185-190. Recuperado de https://doi.org/10.5194/isprs-archives-XLII-3-W4-185-2018

Cruz-Bello, G. M. y Alfie, M. (2018). Environmental perceptions: Participatory methodologies for the assessment of social vulnerability to floods in two communities in Mexico. En L. Antronico y F. Marincioni (eds.), 
Natural hazards and disaster risk reduction policies (pp. 16-35). Calabria, Italia: Geographies of the Anthropocene / Sileno Edizioni.

María Virginia Cervantes Gutiérrez realizó estudios de licenciatura, maestría y doctorado en la Facultad de Ciencias de la Universidad Nacional Autónoma de México. Actualmente es profesora investigadora en el departamento El Hombre y su Ambiente, de la Universidad Autónoma Metropolitana, unidad Xochimilco. Sus líneas de investigación se han orientado a: diagnóstico socioambiental en sistemas ecológicos; manejo sustentable de recursos naturales; implementación y evaluación de acciones de restauración ambiental en sistemas socioecológicos; y análisis de políticas públicas desarrolladas en México sobre restauración. En 1988 recibió el Premio Nacional de Ecología otorgado por la SEDUE, y en 1998 se le otorgó la Medalla Alfonso Caso por sus estudios y tesis de maestría. ORCID: https://orcid. org/0000-0002-1472-8858

Dentro de sus publicaciones relevantes se encuentran:

Cervantes, V., Méndez, I., Roldán, I., Chimal, A., Arriaga, V. y Carabias, J. (2017). Vegetation of a tropical dry forest in a landscape with chronic disturbance: The case of the indigenous community of San Nicolás Zoyatlan (Guerrero, Mexico). Botanical Science, 95(3), 433-459. Recuperado de http://www.botanicalsciences.com.mx/index.php/botani calSciences/article/view/1113/pdf_3

Ortiz Palacios, L., Cervantes-Gutiérrez, V. y Chimal Hernández, A. (2017). Plantas medicinales de San Francisco Tlaltenco, Tláhuac, Ciudad de México. Ciudad de México: Universidad Autónoma Metropolitana, unidad Xochimilco.

Cervantes, V., Carabias, J. y Arriaga, V. (2008). Evolución de las políticas públicas de restauración ambiental en México. En J. Sarukhán (coord.), Capital natural de México. Volumen III: Políticas públicas y perspectivas de sustentabilidad (pp. 155-226). Ciudad de México: Conabio.

Recepción: 1 de enero de 2018.

Aceptación: 20 de julio de 2018. 